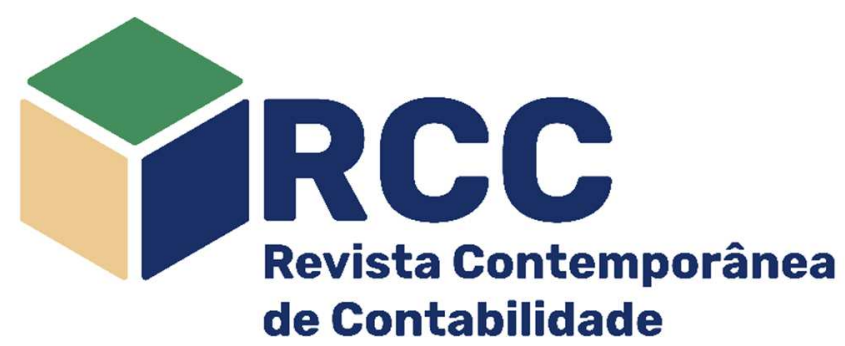

\title{
Dimensões da importância da controladoria nas organizações: um estudo multivariado e multicritério
}

\author{
Dimensions of the importance of controlling in organizations: a multivariate and multicriteria study

\begin{abstract}
Dimensiones de la importancia de la controladora en las organizaciones: un estudio multivariado y
\end{abstract} \\ multicriterio
}

\author{
Silvana Silva Vieira Tambosi ${ }^{\star}$ \\ Doutoranda em Ciências Contábeis e Administração \\ (FURB), Blumenau/SC, Brasil \\ profa.silvana.vieira@gmail.com \\ http://orcid.org/0000-0002-4762-7957 \\ Nelson Hein \\ Doutor em Engenharia de Produção (UFSC) \\ Professor na Universidade Regional de Blumenau (FURB) \\ hein@furb.br \\ https://orcid.org/0000-0002-8350-9480 (1)
}

\author{
Jandir Tambosi Junio \\ Mestre em Administração (FURB), Blumenau/SC, Brasil \\ jrtambosi@gmail.com \\ https://orcid.org/0000-0002-6556-8137 (i)
}

Adriana Kroenke Doutora em Métodos Numéricos e Engenharia (UFPR) Professora na Universidade Regional de Blumenau (FURB)

akroenke@furb.br https://orcid.org/0000-0001-6625-3017 (1)

Endereço do contato principal para correspondência* Rua Antônio da Veiga, n॰ 140, Bairro Itoupava Seca, CEP: 89030-903, Blumenau/SC, Brasil

\begin{abstract}
Resumo
O objetivo que norteou este estudo foi analisar a variabilidade nas respostas dos graduandos do curso de Ciências Contábeis sobre a importância da função da controladoria nas organizações. Para isto, adotou-se uma abordagem quantitativa com base nas perspectivas teóricas dos estudos de Borinelli (2006), a análise descritiva, a técnica multivariada análise fatorial exploratória, e a multicriterial por meio da técnica de entropia da informação. Os principais resultados indicaram que os 234 discentes do curso de Ciências Contábeis apresentaram variabilidade na percepção das atividades da controladoria nas empresas. A dimensão que apresentou maior variação foi a Dimensão 3 "Atividades e Funções da Controladoria Relativas ao Processo de Gestão" (presente nos Fatores 4 e 5). Na percepção dos respondentes as funções da controladoria estão mais relacionadas aos processos operacionais do que aos estratégicos nas organizações.
\end{abstract}

Palavras chave: Controladoria; Controller; Funções da Controladoria

\section{Abstract}

This study's objective was to analyze the variability in the undergraduate students' answers to the importance of organizations' control function. This article adopted a quantitative approach based on the theoretical perspectives of Borinelli's (2006) studies, the descriptive analysis, the multivariate exploratory factorial analysis, and the multicriterial technique through the information entropy technique. The main results indicated that the 234 students of the Accounting Sciences program presented variability in the perception of the controlling companies' activities. Construct 3, "Controlling Activities and Functions Related to the Management Process" (present in Factors 4 and 5), showed the construct that offered the highest variation. In the respondents' perception, the Controller functions are more related to the operational processes than the organizations' strategic ones.

Keywords: Controlling; Controller; Functions of Controlling

\section{Resumen}

El objetivo que orientó este estudio fue analizar la variabilidad en las respuestas de los graduandos del curso de Ciencias Contables sobre la importancia de la función de la controladora en las organizaciones. Para ello, se adoptó un abordaje cuantitativo basado en las perspectivas teóricas de los estudios de Borinelli (2006), el análisis descriptivo, la técnica multivariada análisis factorial exploratorio, y la multicriterial por medio de la técnica de entropía de la información. Los principales resultados indicaron que los 234 discentes del curso de 
Ciencias Contables presentaron variabilidad en la percepción de las actividades de la controladora en las empresas. La dimensión que presentó mayor variación fue la Dimensión 3 "Actividades y Funciones de la Contraloría Relativa al Proceso de Gestión" (presente en los Factores 4 y 5). En la percepción de los respondedores las funciones del controlador están más relacionados a los procesos operativos que a los estratégicos en las organizaciones.

Palabras clave: Controladoria; Controlador; Funciones de la Controladoria

\section{Introdução}

A controladoria nas organizações, inicialmente teve suas funções relacionadas estritamente a área da contabilidade, tais como "contábil, gerencial-estratégica, custos, tributária, gestão da informação, proteção e controle interno dos ativos e dos riscos" (Borinelli, 2006, p. 135).

Entretanto, atualmente a controladoria tem alcançado um espaço maior no planejamento das ações organizacionais (Frezatti et al., 2009; Lunkes et al., 2011; Lourensi \& Beuren, 2011). Sob a perspectiva de mudanças nos cenários econômico e social das empresas, a controladoria vem assumindo papeis estratégicos nas organizações, devido a necessidade do apoio que os gestores demandam de informações econômico-financeiros, análise e simulação de cenários futuros, que podem ser monitoradas e analisadas pelos controllers (Frezatti et al., 2009; Lunkes et al., 2011).

Tais mudanças, quanto a função da controladoria nas organizações, ainda está em processo de discussão pelos teóricos e profissionais da área, ou seja, há uma variabilidade na compreensão acerca da atuação da controladoria nas empresas. Entretanto, a clareza conceitual e atribucional deve-se tornar reconhecidas pelos especialistas que atuam nessa área (Lourensi \& Beuren, 2011). Essa dissonância conceitual entre os pesquisadores, favorecem a inconsistência da literatura sobre o tema. Pois, à medida que alguns estudiosos conceituam a controladoria como uma posição de apoio gerencial, outros a classificam como uma atividade da contabilidade para fins externos (Borinelli, 2006; Lunkes, Gasparetto \& Schnorrenberger, 2010).

Desta forma, o entendimento acerca do papel da controladoria na empresa se faz importante. Em especial, pelas Instituições de Ensino Superior (IES) que preparam futuros profissionais (graduandos) para atuar nesta área.

Alguns estudos já apontam a preocupação das IES na formação dos seus acadêmicos, frente as novas demandas advindas das mudanças provocadas por uma conjuntura mundial, estimulando reflexões sobre seu papel na capacitação dos seus acadêmicos para assumir postos de trabalhos que requerem uma nova abordagem. Além disso, buscam conhecer os impactos da formação dos estudantes na atuação acadêmica e profissional (Siegel; \& Kulesza, 1996a; Siegel \& Kulesza, 1996b; Siegel, Kulesza \& Sorensen, 1997; Frezatti \& Kassai, 2003; Rodrigues \& Amaral, 2006; Peleias et al., 2011; Mondini, Tambosi \& Lavarda, 2015).

Sob esta perspectiva, levanta-se a seguinte questão de pesquisa: Qual a variabilidade na compreensão, entre os graduandos do curso de ciências contábeis, sobre a importância da função da controladoria nas organizações? Busca-se reaver se há intercorrência na percepção dos estudantes desta área. Os especialistas reconhecem que algumas práticas da área de controladoria possuem variações entre as organizações, devido as suas características, tais como: porte, ramo de atividade, região, etc. Contudo, apesar de tratar-se de uma área composta por conhecimentos interdisciplinares, é necessário que os princípios fundamentais da função da controladoria mantenham-se, pois são reguladoras a sua área de conhecimento e atuação (Borinelli, 2006).

\section{Fundamentação Teórica}

A área de controle de gestão desenvolveu-se na década de 60 , baseado na contabilidade. Trata-se de uma abordagem tradicional da controladoria, que é um modo pelo qual os gestores asseveram que os recursos são adquiridos e aproveitados de forma eficiente e eficaz na concretização dos objetivos da organização (Anthony, 1965; Lowe \& Puxty, 1989; Merchant, 1989; Otley, 1990; Otley, 1994).

Entretanto, houveram algumas mudanças no papel da controladoria nas organizações, devido a um novo ambiente econômico que instigou mudanças na estrutura das organizações. Fatores como a incerteza, tamanho da organização, concentração e alianças, declínio da produção (Odey \& Berry, 1980). Estes fatores trouxeram algumas implicações para o controle de gestão: a existência do controle de gestão, a orientação de processos de negócios, balanced scorecard, competição, flexibilidade (Lowe, 1971; Kaplan \& Norton, 2005).

Em uma visão mais contemporânea, a controladoria é uma área nas organizações que tem como diligência a eficácia nos processos internos e externos de gestão, assegurando que todos os envolvidos (stakeholders) tenham acesso as informações necessárias para o desenvolvimento de seus trabalhos. A controladoria é uma área em que o conhecimento se dissemina, ajusta-se as demandas para que possam ser implementadas nos sistemas de informações contábeis e gerenciais das empresas (Frezatti et al., 2009).

Quanto as funções específicas atribuídas a controladoria, Borinelli (2006, p. 135) lista a "contábil, 
gerencial-estratégica, custos, tributária, gestão da informação, proteção e controle interno, dos ativos e dos riscos." No entanto, Lunkes et al. (2011), salientam que, além do gerenciamento das informações, a controladoria deve ter ativa participação nas decisões organizacionais por meio do processo de planejamento estratégico.

Corroborando Frezatti et al. (2009), os autores Lourensi e Beuren (2011, p. 02) reiteram em seu estudo que "a controladoria assume cada vez mais papel preponderante no contexto administrativo das organizações. Ao prover informações de suporte ao processo de gestão, ela intenta contribuir para a continuidade dessas organizações." Entretanto, ponderam seu alcance por considerarem a controladoria como uma "área de conhecimento relativamente nova, e persistem ainda dúvidas sobre sua conceituação, seu papel no processo de gestão e os procedimentos por ela adotados como órgão administrativo." (Lourensi \& Beuren, 2011, p. 02).

Com isto posto, a pesquisa de Lourensi and Beuren (2011) buscou analisar a inserção da Controladoria, sob as perspectivas propostas por Borinelli (2006): conceituais, procedimentais e organizacionais. O primeiro aspecto (conceitual) abordou o estudo da área de conhecimento nominada como controladoria. O segundo aspecto (procedimento) foi investigado os princípios relacionados ao seu funcionamento, ou seja, trata das funções inerentes a controladoria nas organizações. O terceiro elemento (organizacional) tratou-se do modo como as funções e práticas da controladoria são entendidas e tratadas nas instituições.

Assim, as funções da controladoria não se limitam a realizar e divulgar informações contábeis, que apesar de importantes, não são suficientes para abranger o processo macro de gestão. Tal observação é relevante, uma vez que a controladoria é a área da organização responsável em elaborar dados econômicofinanceiros, importantes para que os controllers possam apoiar os gestores nas tomadas de decisões, auxiliando no alcance dos objetivos organizacionais (Frezatti et al., 2009).

Com relação as funções do controller nas organizações, na década de 40 estudos apontavam uma discrepância nas atividades dos controllers nos setores das empresas, o que demonstrou uma ausência na clareza na definição desta função (FISKE, 1940). A ausência consensual de tal definição permaneceu impreciso até a década de 80, conforme destacou o autor Yoshitake (1982) em seu estudo.

Segundo Frezatti et al. (2009, p. 29) "durante anos, o controller teve como função apenas a realização da contabilidade formal, a preparação de registros contábeis-financeiros e a custódia dos ativos da empresa". A função do controller limitava-se a elaborar informações técnicas, considerando apenas o desempenho financeiro da empresa (Otley, 1999).

De modo gradual é que as funções deste profissional foram sendo ampliadas, começando a realizar análises e explicações mais aprofundadas. É importante destacar também que a ampliação na função do controller, ocorreu após a criação do Controllers Institute of America. Esta é uma organização empenhada no aprimoramento da área e dos profissionais da controladoria (Macdonald, 1940).

Além do apoio de organizações como Controllers Institute of America, as mudanças na função do controller atribuísse também as novas necessidades requeridas pelas empresas no contexto mais atual. $O$ autor pontua, em especial, o surgimento do mercado de capitais, que fez com que a contabilidade atuasse de forma que pudesse apoiar os gestores acompanhando o seu desempenho, assegurando assim os interesses dos acionistas e investidores (Frezatti et al., 2009).

No que tange o papel do controller nas organizações e a formação desses profissionais, os autores Siegel e Kulesza (1996a); Siegel e Kulesza (1996b); Siegel et al. (1997); Frezatti e Kassai (2003); Rodrigues e Amaral, (2006); Peleias et al. (2011); Oro, Beuren e Carpes (2013); Mondini et al. (2015) salientam que apesar da interdisciplinaridade na atuação desses profissionais, é imprescindível que haja uma reflexão acerca dos currículos acadêmicos no ensino da controladoria nas IES. O propósito é capacitar seus graduandos para assumir posições no mercado de trabalho que demandam uma nova abordagem, de organizações que necessitam de apoiadores no planejamento e na tomada de decisões estratégicas.

Ainda, o ensino da controladoria nos cursos de ciências contábeis foi requerido pelo Conselho Federal de Educação, a partir da Resolução CNE/CES 10 de 16 de dezembro de 2004. Ademais, cônscios da consolidação conceitual sobre a controladoria, estudiosos da área vem buscando definir e identificar as competência e habilidades inerentes a atividade (Borinelli, 2006; Rodrigues \& Amaral, 2006; Beuren \& Grande, 2008; Carvalho Júnior \& Rocha, 2009; Lunkes et al., 2010; Lunkes et al., 2012; Paiva \& Facci, 2014; Araújo, Callado \& Cavalcanti, 2014; Gomes, Souza \& Lunkes, 2014; Schnorrenberger, Castro \& Lunkes, 2015).

\subsection{Estudos anteriores sobre o modelo de pesquisa utilizado}

As pesquisas anteriores que utilizaram o mesmo modelo adotado neste estudo, demonstraram discordâncias na parte conceitual da temática de controladoria. Borinelli (2006) organizou e apresentou as definições de forma sistematizada, identificando a discordância conceitual entre os teóricos da área, principalmente no que se refere as funções da controladoria e o papel deste profissional nas empresas.

Conforme já mencionado no capítulo anterior, o autor classifica teoricamente a controladoria sob três aspectos: conceituais, procedimentais e organizacionais. Para Borinelli (2006, p.105) a controladoria "é um 
conjunto de conhecimentos que se constituem em bases teóricas e conceituais de ordens operacional, econômica, financeira e patrimonial, relativas ao controle do processo de gestão organizacional". Posteriormente, é elencado as funções que contempla à controladoria, e por último, pondera a ordenação destas funções nas diversas áreas da organização.

Outras pesquisas, tais como dos autores Beuren e Grande (2008); Lourensi e Beuren (2011); Mondini et al. (2015) suportam o modelo proposto por Borinelli (2006) perante os âmbitos conceituais, procedimentais e organizacionais. Beuren e Grande (2008) adotaram o modelo de Borinelli (2006) a fim de identificar as abordagens relativas à temática em publicações nacionais. Os resultados revelaram que, a controladoria, é pouco examinada como uma área do conhecimento em publicações nacionais. $O$ foco das literaturas nacionais, acerca das atividades pertinentes a controladoria, concentram-se em abordar os processos que administram as informações.

Seguidamente, Lourensi e Beuren (2011) empregaram novamente as perspectivas conceituais sugeridas por Borinelli (2006) para analisar a inclusão da controladoria nas teses de doutoramento defendidas no programa da FEA/USP entre o período de 1997 e 2006. Constataram que, com relação as questões conceituais, procedimentais e organizacionais, o tema da controladoria é pouco significativo nas discussões e análises desses trabalhos.

O estudo de Mondini et al. (2015), investigou o entendimento dos estudantes que já haviam cursado a disciplina de controladoria, com os estudantes que atuavam no setor de controladoria de uma empresa, acerca da função do controller nas organizações, medidos também a partir do modelo de Borinelli (2006). Os resultados indicaram que há uma concordância, entre os pesquisados, de que as funções da controladoria estão relacionadas a atividades operacionais, mas também as áreas estratégicas. Tal dado sinaliza que a controladoria vem sendo cada vez mais percebida como uma função com foco mais estratégico nas empresas.

\section{Métodos e Técnicas de Pesquisa}

Nesta seção descreve-se o enquadramento metodológico da pesquisa e os procedimentos para coleta e análise dos dados.

\subsection{Enquadramento Metodológico}

A fim de responder o objetivo deste estudo, que foi analisar a variabilidade nas respostas dos graduandos do curso de ciência contábeis sobre a importância da função da controladoria nas organizações, adotou-se o método quantitativo tanto na abordagem quanto no tratamento dos dados por meio de técnicas estatística multivariada e multicritério.

O método quantitativo tem como finalidade mensurar os dados levantados, por meio da coleta de informações, a análise de dados numéricos, e aplicando testes estatísticos. A validade de estudos quantitativos ocorre por meio da confiabilidade de indicadores estatísticos (Hair, 2009; Collis \& Hussey, 2013). Com relação a técnica de pesquisa, adotou-se a descritiva, que segundo Hair (2009) é uma técnica utilizada normalmente para examinar as características de eventos ou atividades de pesquisa, de forma estruturada.

O método multicritério é uma análise sistemática que busca identificar, caracterizar e classificar os principais fatores constituintes, por meio da comparação entre as variáveis propostas em um conjunto de critérios. O intuito é oferecer possíveis alternativas sobre as preferências do grupo envolvido no processo decisório (Matzenauer, 2003; Gomes, Autran, Araya \& Carignano, 2004; Stewart, 2011; Almeida, 2013).

\subsection{Procedimentos de Coleta e Análise dos Dados}

Com relação ao instrumento utilizado para a coleta dos dados, utilizou-se as dimensões e indicadores propostos por Borinelli (2006). O instrumento foi composto por 48 questões divididas em quatro dimensões (Quadro 1), com a escala de mensuração de tipo Likert de 7 pontos, com variâncias entre 1, para discordo totalmente e 7, concordo totalmente.

Além das proposições adotadas do modelo de Borinelli (2006), o questionário continha questões acerca do perfil dos respondentes, tais como: Gênero; Idade; Instituição de Ensino; Semestre do cursante; se já cursou ou está cursando a disciplina de controladoria e se o acadêmico atua na área de controladoria. $O$ questionário estruturado foi disponibilizado em duas versões: via Google Forms e impressa, aplicada em uma Instituição de Ensino Superior, respondidos por graduandos do curso de Ciências Contábeis. A coleta dos dados ocorreu no primeiro semestre letivo de 2015, e obteve-se 234 respondentes.

Em seguida, os dados foram tabulados em planilha do software Microsoft Exceß $\AA^{\circledR}$. As questões foram agrupadas de acordo com as dimensões propostas (Figura 1). A base de dados da planilha do software Microsoft Exceß foi importada para o Software Estatístico SPSS $\AA^{\circledR}$ versão 22. A primeira análise realizada foi a fatorial exploratória. Trata-se de uma técnica estatística multivariada que analisa o padrão de correlações existentes entre as variáveis e, por meio destes padrões, busca-se agrupar suas variáveis em fatores. 0 objetivo é verificar a existência de estruturas que não podem ser observadas diretamente (Corrar, Paulo \& 
Dias Filho, 2007).

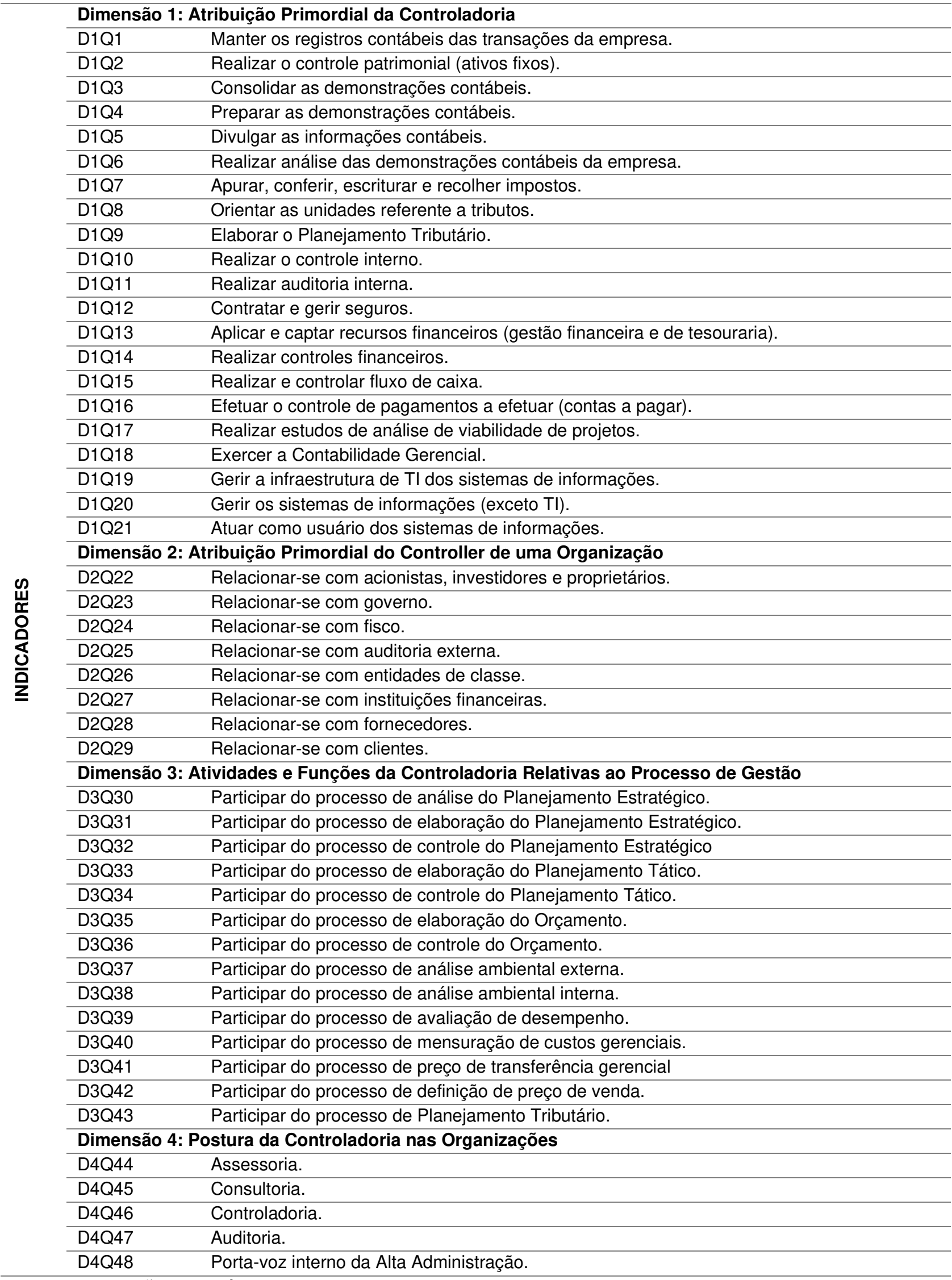

Figura 1. Dimensões e variáveis da controladoria nas empresas

Fonte: Adaptado de Borinelli (2006); Mondini et al. (2015).

A segunda análise realizada foi a multicriterial de entropia da informação. Este método é utilizado para determinar o peso da informação presente nos indicadores avaliados (Zeleny, 1982; Zou, Yi \& Sun, 
2006). Originalmente, o termo entropia procedeu-se da termodinâmica, e com o tempo foi sendo utilizado em outras áreas do conhecimento, como as ciências sociais (Rocha et al, 2011).

Para o cálculo da entropia, foi necessário um ponto de referência, isto é, um valor âncora em referência ao valor em que é calculada a entropia da informação. Nesta pesquisa 0 valor atribuído foi 7 (Concordo Totalmente). Desta forma, o valor da entropia alcançado recomendará o quanto de informação está presente em cada questão do instrumento de pesquisa utilizado (Zeleny, 1982; Rocha et al, 2011).

Para a viabilização da análise dos dados levantados, buscou-se verificar a variabilidade nas respostas quanto à concordância e discordância dos atributos (questões). Para isto, matematicamente aplicou-se o seguinte modelo matemático, conforme Zeleny (1982) e Rocha et al. (2011):

$$
d_{i}=\left(d_{i}^{1}, d_{i}^{2}, \ldots, d_{i}^{m}\right) \text { os valores normalizados, no qual: } d_{i}^{k}=\frac{x_{i}^{K}}{X_{i}^{*}} \text {, caracterizando o conjunto } \mathrm{D} \text {, na forma }
$$

do i-ésimo atributo. Define-se $D_{i}=\sum_{k=1}^{m} d_{i}^{k} ; \mathrm{i}=1,2, \ldots, \mathrm{n}$. A medida de entropia do contraste de intensidade para o i-ésimo atributo é calculado por $\mathrm{e}\left(d_{1}\right)=-\alpha=\sum_{k=1}^{m} \frac{d_{i}^{k}}{D_{i}} \operatorname{Ln}\left(\frac{d_{i}^{k}}{D_{1}}\right)$, onde $\alpha=\frac{1}{e_{\max }}>0$ e $e_{\max }=\operatorname{Ln}(\mathrm{m})$. Recordando ainda que $0 \leq d_{i}^{k} \leq 1$ e $d_{i}^{k} \geq 0$. Na ocorrência de todos os $\mathrm{k}$ i d forem idênticos para um dado i, em tal caso $\frac{d_{i}^{k}}{D_{i}}=\frac{1}{n}$ e e $\left(d_{i}\right)$ admite valor máximo, ou seja, $e_{\max }=\operatorname{Ln}(\mathrm{m})$. Fixando $\alpha=\frac{1}{e_{\max }}$ designa-se $0 \leq \mathrm{e}\left(d_{i}\right) \leq 1$ para todos os $d_{i}$ 's. Tal normalização é imprescindível para efeito de comparação. A entropia total de $D$ é determinada por: $E=\sum_{i=1}^{n} e\left(d_{i}\right)$.

Por motivo do peso $\lambda_{i}^{\sim}$ ser opostamente concatenado a e $\left(d_{i}\right)$ é utilizado $1-\mathrm{e}\left(d_{i}\right)$ ao contrário de $\mathrm{e}\left(d_{i}\right)$ e normaliza-se para garantir que $0 \leq 0 \quad \lambda_{i}^{\sim} \leq 1$ e $\sum_{i=1}^{n} \lambda_{i}^{\tilde{i}}=1$. Assim, tem-se: $\lambda_{i}^{\tilde{}}=\frac{1}{n-E}\left[1-e\left(d_{i}\right)\right]=\frac{\left[1-e\left(d_{i}\right)\right]}{n-E}$.

\section{Apresentação e Análise dos Resultados}

Neste capítulo serão apresentados e discutidos os resultados da pesquisa. Na primeira parte, apresenta-se o perfil dos estudantes, em seguida são apresentados os dados das dimensões do modelo de Borinelli (2006). Estas dimensões foram analisadas utilizando a técnica estatística multivariada análise fatorial exploratória, e em seguida, foi realizada análise da variabilidade das informações, a partir da análise multicriterial fazendo uso da técnica de entropia da informação, a fim de responder ao objetivo desse estudo: analisar a variabilidade nas respostas dos graduandos do curso de ciência contábeis sobre a importância da função da controladoria nas organizações.

Preliminarmente foi realizada uma análise descritiva para conhecer o perfil dos respondentes, em que abrangeu o gênero, idade, se o respondente já cursou ou está cursando a disciplina de controladoria e se o mesmo atua profissionalmente na área de controladoria (Tabela 1).

Tabela 1:

Perfil dos Respondentes

\begin{tabular}{|c|c|c|c|c|c|c|c|}
\hline \multicolumn{2}{|c|}{ GÉNERO (\%) } & \multicolumn{6}{|c|}{ IDADE (anos em \%) } \\
\hline Fem. & Masc. & $18-28$ & $29-39$ & $40-50$ & & $51-61$ & Acima de 61 \\
\hline $58 \%$ & $42 \%$ & $85 \%$ & $12,5 \%$ & $1,2 \%$ & & $10 \%$ & $3 \%$ \\
\hline \multicolumn{5}{|c|}{ Sobre a Disciplina de Controladoria (\%) } & \multicolumn{3}{|c|}{ Trabalha na Área de Controladoria (\%) } \\
\hline \multicolumn{4}{|c|}{ Está cursando neste semestre. } & $30,6 \%$ & \multirow{2}{*}{\multicolumn{2}{|c|}{ Sim }} & $10,4 \%$ \\
\hline \multicolumn{4}{|c|}{ Já cursou. } & $57,9 \%$ & & & \\
\hline $\begin{array}{l}\text { Estud } \\
\text { discip }\end{array}$ & $\begin{array}{l}\text { o tem } \\
\text { do curss }\end{array}$ & ontrola & em outra & $11,5 \%$ & \multicolumn{2}{|l|}{ Não } & $89,6 \%$ \\
\hline
\end{tabular}

Fonte: dados da pesquisa

Verifica-se na Tabela 1 que a maioria (58\%) dos estudantes é do gênero feminino e faixa etária entre 18 e 28 anos (85\%). Quanto à disciplina de Controladoria, 57,9\% responderam que já cursaram, 30,6\% estão cursando no semestre em que a pesquisa foi aplicada, e 11,5\% ainda não cursaram, entretanto já estudaram o tema em outras disciplinas oferecidas pelo curso. Ainda, é interessante observar que a maioria dos estudantes $(89,6 \%)$ não atua na área de controladoria, assim a percepção dos estudantes quanto a função da controladoria nas organizações baseia-se nos ensinamentos dos professores do curso.

Entende-se que estes, por sua vez, são especialistas e pesquisadores na área de controladoria, que devem possuir o entendimento sobre o tema sob as três perspectivas de Borinelli (2006) que são: conceituais, procedimentais e organizacionais.

A seguir nas Tabelas 2, 3, 4 e 5 são apresentados os testes estatísticos da análise fatorial exploratória. 
Tabela 2:

Teste de KMO e Bartlett

\begin{tabular}{lc|l}
\hline \multicolumn{2}{l|}{ Medida Kaiser-Meyer-Olkin de adequação de amostragem. } & 0,831 \\
\hline Teste de esfericidade de Qui-quadrado aprox. & 6283,492 \\
Bartlett & $\mathrm{df}$ & 1081 \\
& Sig. & 0,000 \\
\hline
\end{tabular}

Fonte: dados da pesquisa

De acordo com a Tabela 2 percebe-se que o KMO apresentou um bom nível de confiança, visto que o valor foi 0,831 . O teste de Bartlett confirma que o conjunto de itens pode representar o construto (Fávero et al., 2009).

Tabela 3:

Comunalidades

\begin{tabular}{l|l|l|l|l|l}
\hline Questões & Inicial & Extração & Questões & Inicial & Extração \\
\hline D1Q1 & 1,000 & 0,760 & D2Q26 & 1,000 & 0,613 \\
\hline D1Q2 & 1,000 & 0,727 & D2Q27 & 1,000 & 0,727 \\
\hline D1Q3 & 1,000 & 0,837 & D2Q28 & 1,000 & 0,673 \\
\hline D1Q4 & 1,000 & 0,853 & D2Q29 & 1,000 & 0,638 \\
\hline D1Q7 & 1,000 & 0,726 & D3Q31 & 1,000 & 0,770 \\
\hline D1Q8 & 1,000 & 0,723 & D3Q32 & 1,000 & 0,757 \\
\hline D1Q9 & 1,000 & 0,755 & D3Q33 & 1,000 & 0,760 \\
\hline D1Q13 & 1,000 & 0,744 & D3Q34 & 1,000 & 0,789 \\
\hline D1Q14 & 1,000 & 0,734 & D3Q35 & 1,000 & 0,801 \\
\hline D1Q15 & 1,000 & 0,736 & D3Q36 & 1,000 & 0,798 \\
\hline D1Q16 & 1,000 & 0,715 & D3Q37 & 1,000 & 0,783 \\
\hline D1Q18 & 1,000 & 0,639 & D3Q40 & 1,000 & 0,736 \\
\hline D1Q19 & 1,000 & 0,613 & D3Q41 & 1,000 & 0,672 \\
\hline D1Q20 & 1,000 & 0,660 & D3Q42 & 1,000 & 0,671 \\
\hline D1Q21 & 1,000 & 0,697 & D3Q43 & 1,000 & 0,725 \\
\hline D2Q23 & 1,000 & 0,687 & D4Q44 & 1,000 & 0,735 \\
\hline D2Q24 & 1,000 & 0,740 & D4Q45 & 1,000 & 0,662 \\
\hline D2Q25 & 1,000 & 0,671 & D4Q47 & 1,000 & 0,767 \\
\hline
\end{tabular}

Fonte: dados da pesquisa

Conforme apresentado na Tabela 3 foi realizado o método de extração para análise do componente principal. Ou seja, é verificada a força da questão com relação as demais questões. Assim, a questão que obteve menor relação com as demais deve ser excluída do grupo $(<0,35)$ (HAIR, 2009). Neste estudo, as questões excluídas foram: D1Q6, D1Q10, D1Q11, D1Q12, D1Q17, D2Q22, D3Q39, D4Q46, D4Q48.

Tabela 4:

Variância Total Explicada

\begin{tabular}{|c|c|c|c|c|c|c|c|c|c|}
\hline \multirow{2}{*}{ 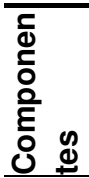 } & \multicolumn{3}{|c|}{ Valores próprios iniciais } & \multicolumn{3}{|c|}{$\begin{array}{l}\text { Somas de extração } \\
\text { carregamentos ao quadrado }\end{array}$} & \multicolumn{3}{|c|}{$\begin{array}{l}\text { de Somas rotativas de carregamentos } \\
\text { ao quadrado }\end{array}$} \\
\hline & Total & $\begin{array}{l}\% \\
\text { variância }\end{array}$ & de $\%$ cumulativa & Total & $\begin{array}{l}\% \\
\text { variância }\end{array}$ & de $\%$ cumulativa & Total & $\begin{array}{l}\% \\
\text { variância }\end{array}$ & de $\%$ cumulativa \\
\hline $1+$ & 9,838 & 25,890 & 25,890 & 9,838 & 25,890 & 25,890 & 4,723 & 12,430 & 12,430 \\
\hline$\overline{2}$ & 4,434 & 11,667 & 37,557 & 4,434 & 11,667 & 37,557 & 3,894 & 10,249 & 22,679 \\
\hline$\overline{3}$ & 2,504 & 6,589 & 44,146 & 2,504 & 6,589 & 44,146 & 3,510 & 9,237 & 31,916 \\
\hline$\overline{4}$ & 1,980 & 5,211 & 49,358 & 1,980 & 5,211 & 49,358 & 2,901 & 7,634 & 39,550 \\
\hline 5 & 1,801 & 4,739 & 54,097 & 1,801 & 4,739 & 54,097 & 2,619 & 6,891 & 46,441 \\
\hline
\end{tabular}

Método de extração: análise do componente principal.

Fonte: dados da pesquisa

Na Tabela 4 observa-se que os cinco primeiros componentes já correspondem a 54,09\% da variância. Optou-se por não considerar os demais componentes, pois os valores começaram a ficar diminutos em relação ao número de variáveis. 
Tabela 5:

Matriz de componente rotativa

\begin{tabular}{|c|c|c|c|c|c|c|c|c|c|c|}
\hline \multirow[b]{2}{*}{ Questões } & \multicolumn{10}{|c|}{ Componente } \\
\hline & 1 & 2 & 3 & 4 & 5 & 6 & 7 & 8 & 9 & 10 \\
\hline D1Q4 & 853 & & & & & & & & & \\
\hline$\overline{\mathrm{D} 1 \mathrm{Q} 1}$ & ,831 & & & & & & & & & \\
\hline D1Q3 &, 830 & & & & & & & & & \\
\hline$\overline{\mathrm{D} 1 \mathrm{Q7}}$ & ,735 & & & & & & & & & \\
\hline D1Q5 & ,719 & & & & & & & & & \\
\hline D1Q2 & 695 & & & & & & & & & \\
\hline$\overline{\mathrm{D} 1 \mathrm{Q} 15}$ & &, 806 & & & & & & & & \\
\hline$\overline{\text { D1Q14 }}$ & &, 793 & & & & & & & & \\
\hline$\overline{\text { D1Q16 }}$ & &, 729 & & & & & & & & \\
\hline D1Q13 & &, 717 & & & & & & & & \\
\hline$\overline{\text { D2Q29 }}$ & &, 566 &, 454 & & & & & & & \\
\hline D2Q24 & & &, 763 & & & & & & & \\
\hline$\overline{\text { D2Q23 }}$ & & &, 729 & & & & & & & \\
\hline$\overline{\mathrm{D} 2 \mathrm{Q} 27}$ & &, 405 &, 696 & & & & & & & \\
\hline$\overline{\mathrm{D} 2 \mathrm{Q} 25}$ & & &, 692 & & & & & & & \\
\hline D2Q26 & & &, 687 & & & & & & & \\
\hline D2Q28 & &, 524 &, 542 & & & & & & & \\
\hline$\overline{\mathrm{D} 3 \mathrm{Q} 32}$ & & & & 855 & & & & & & \\
\hline D3Q31 & & & & 838 & & & & & & \\
\hline$\overline{\text { D3Q33 }}$ & & & &, 586 & &, 376 & & & & \\
\hline D3Q34 & & & &, 559 & &, 478 & & & & \\
\hline D1Q18 & & & &, 518 & ,370 & & & & & \\
\hline$\overline{\mathrm{D} 3 \mathrm{Q} 40}$ & & & & & ,787 & & & & & \\
\hline D3Q41 & & & & & ,786 & & & & & \\
\hline$\overline{\mathrm{D} 3 \mathrm{Q} 42}$ & & & & & ,665 & & & & & \\
\hline D3Q43 & & & & & ,488 & & & & 470 & \\
\hline D3Q36 & & & & & &, 803 & & & & \\
\hline D3Q35 & & & & & & ,796 & & & & \\
\hline D3Q37 & & & & & & & 878 & & & \\
\hline D3Q38 & & & & & & & ,863 & & & \\
\hline D4Q45 & & & & & & & &, 826 & & \\
\hline D4Q44 & & & & & & & &, 777 & & \\
\hline D1Q9 & & & & & & &, 406 & &, 598 & \\
\hline D4Q47 & & & & & & & &, 410 &, 531 & \\
\hline D1Q8 &, 456 & & & & & & & &, 516 & \\
\hline D1Q20 & & & & & & & & & & ,696 \\
\hline$\overline{\text { D1Q19 }}$ & &, 491 & & & & & & & &, 598 \\
\hline D1Q21 & & & & ,384 & & & & & &, 593 \\
\hline
\end{tabular}

Método de extração: Análise do Componente principal.

Método de rotação: Varimax com normalização de Kaiser.

a. Rotação convergida em 20 iterações.

Fonte: dados da pesquisa

Conforme apresentado na Tabela 5, dos 48 itens pesquisados, 38 itens podem ser agrupados em dez dimensões. Entretanto, neste estudo optou-se por considerar os fatores que obtiveram no mínimo quatro questões agrupadas no mesmo fator de explicação, ou seja, os cinco primeiros fatores, conforme já explicado também na Tabela 4.

Em seguida, calculou-se a entropia da informação de cada componente ou item, redimensionados pela fatorial exploratória (Tabela 6).

Após rodar o modelo matemático, utilizado para calcular a entropia da informação de cada questão, levantada no instrumento aplicado para este estudo (Tabela 6), verificou-se que as informações mais relevantes presentes no Fator 1 (Dimensão 1) "Atribuição Primordial da Controladoria", de acordo com os respondentes, foram: D1Q7 "Apurar, conferir, escriturar e recolher impostos" (26,45\%) e D1Q4 "Preparar as demonstrações contábeis" (19\%). A questão que houve menos informação $(8,67 \%)$ foi a D1Q2 "Realizar o controle patrimonial (ativos fixos)". 
Tabela 6:

Entropia da Informação

\begin{tabular}{|c|c|c|c|}
\hline \multicolumn{2}{|c|}{ Variáveis } & Entropia e $\left(d_{i}\right)$ & Peso \\
\hline \multirow{6}{*}{ Fator 1} & D1Q4 & 0,974542854 & 0,189734873 \\
\hline & D1Q1 & 0,97984178 & 0,150241401 \\
\hline & D1Q3 & 0,980890691 & 0,142423757 \\
\hline & D1Q7 & 0,964506099 & 0,264539897 \\
\hline & D1Q5 & 0,977677911 & 0,166368952 \\
\hline & D1Q2 & 0,988368461 & 0,08669112 \\
\hline \multirow{6}{*}{ Fator 2} & D1Q15 & $-0,982208193$ & 0,166956934 \\
\hline & D1Q14 & $-0,984135998$ & 0,167119309 \\
\hline & D1Q16 & $-0,969856224$ & 0,165916555 \\
\hline & D1Q13 & $-0,971953344$ & 0,166093191 \\
\hline & D2Q29 & $-0,981031704$ & 0,166857841 \\
\hline & D2Q28 & $-0,983386377$ & 0,16705617 \\
\hline \multirow{5}{*}{ Fator 3} & D2Q24 & 0,981994429 & 0,23310405 \\
\hline & D2Q23 & 0,980166597 & 0,256767567 \\
\hline & D2Q27 & 0,986564013 & 0,012472573 \\
\hline & D2Q25 & 0,990578048 & 0,121978646 \\
\hline & D2Q26 & 0,98345428 & 0,214204511 \\
\hline \multirow{5}{*}{ Fator 4} & D3Q32 & 0,994873567 & 0,138148737 \\
\hline & D3Q31 & 0,994094124 & 0,159153403 \\
\hline & D3Q33 & 0,990945217 & 0,244011142 \\
\hline & D3Q34 & 0,991757338 & 0,222125866 \\
\hline & D1Q18 & 0,991221683 & 0,236560852 \\
\hline \multirow{4}{*}{ Fator 5} & D3Q40 & 0,992017898 & 0,165282518 \\
\hline & D3Q41 & 0,987821047 & 0,252185224 \\
\hline & D3Q42 & 0,986279227 & 0,284111129 \\
\hline & D3Q43 & 0,985588145 & 0,298421129 \\
\hline
\end{tabular}

Fonte: dados da pesquisa

Analisando os dados desta dimensão, percebe-se que os respondentes entendem como sendo funções fundamentais da controladoria atividades processuais. Este dado corrobora o entendimento de Borinelli (2006) quanto as funções que são inerentes a controladoria, sob o aspecto procedimental, ou seja, atividades relacionadas ao funcionamento da controladoria.

Com relação ao segundo fator, composto por questões das Dimensões 1 e 2 do instrumento de Borinelli (2006) "Atribuição Primordial da Controladoria" e "Atribuição Primordial do Controller de uma Organização", houve uma homogeneização das respostas. Ou seja, as seis questões presentes neste fator possuem em média 16\% de informação (variações entre: 16,60\% e 16,71\%), não apresentando variabilidade acentuada entre as informações. Os itens que agruparam neste fator tratam de questões relacionadas a realização de controles financeiros, controle de fluxo de caixa, controle de pagamentos, aplicação e captação de recursos financeiros, relacionamento com clientes e fornecedores.

Como pode-se observar, as funções percebidas como sendo do Controller ainda estão relacionadas as atividades procedimentais. Segundo Otley (1999) e Frezatti et al. (2009) perdurantemente, as funções designadas a este profissional estão relacionadas a execução formal da contabilidade, como a organização de registros contábeis financeiros. Limitando assim a sua atuação apenas na elaboração de informações técnicas, levando em conta apenas o desempenho financeiro da organização.

Quanto ao Fator três, composto por questões da Dimensão 2 "Atribuição Primordial do Controller de uma Organização", esta trata do relacionamento do Controller com as instituições que provém informações importantes para a empresa: D2Q23 "Relaciona-se com o governo" (26\%); D2Q24 "Relaciona-se com o fisco" (23,31\%); D2Q26 "Relaciona-se com entidades de classe" $(21,42 \%)$. Por outro lado, a questão que houve menor representatividade foi D2Q27 "Relacionar-se com instituições financeiras" (1,25\%). É interessante observar que as questões que tratam da relação do Controller com acionistas, investidores e proprietários não foram atribuídas ao Controller. Tal fato reforça ainda mais os dados discutidos anteriormente no Fator 2.

Vale destacar que, o relacionamento com estes stakeholders, possibilita ao Controller um posicionamento mais estratégico, e não apenas operacional na organização. De acordo com Frezatti et al. (2009) além da organização das informações, é também atribuição do Controller assegurar aos stakeholders acesso as informações cogentes para a execução de seus trabalhos. Enfatiza-se também que a controladoria é responsável em elaborar dados econômico-financeiros, para que os Controller possam apoiar os gestores nas tomadas de decisões, auxiliando no alcance dos objetivos organizacionais. 
Com relação ao Fator quatro verificou-se que os itens mais relevantes presentes neste fator (Dimensão 3) "Atividades e Funções da Controladoria Relativas ao Processo de Gestão" e (Dimensão 1) "Atribuição Primordial da Controladoria", foram: D3Q33 "Participar do processo de controle do Planejamento Tático" (24,40\%); D1Q18 "Exercer a Contabilidade Gerencial" (23,66\%); D3Q34 "Participar do processo de elaboração do Orçamento" (22,21\%). No entanto, as questões que apresentaram o menor percentual de informação foram: D3Q31 "Participar do controle do Planejamento Estratégico" (15,91\%) e D3Q32 "Participar do processo de elaboração do Planejamento Tático" (13,81\%).

Infere-se que estes dados refletem a percepção dos estudantes a partir da visão dos seus docentes e a bibliografia disponível, quanto a função da controladoria e do controller nas organizações, nas quais as atividades da controladoria estão mais relacionadas a atividades operacionais do que as estratégicas. Este dado corrobora a pesquisa de Beuren e Grande (2008); Lourensi e Beuren (2011), em seus estudos identificaram que a controladoria era pouco explorada como área do conhecimento em publicações nacionais, e que as literaturas nacionais tratam das funções da controladoria como sendo processos que administram as informações.

Por fim, no Fator cinco as questões que concentraram mais informações neste fator (Dimensão 3) "Atividades e Funções da Controladoria Relativas ao Processo de Gestão" foram: D3Q43 "Participar do processo de Planejamento Tributário" (29,84\%); D3Q42\% "Participar do processo de definição de preço de venda" (28,41\%); D3Q41 "Participar do processo de preço de transferência gerencial" (25,22\%). Conquanto, a questão que apresentou menos informação foi a D3Q40 "Participar do processo de mensuração de custos gerenciais" (16,53\%).

Analisando as informações que foram mais preponderantes no Fator cinco, os respondentes consideram importante a controladoria participar dos processos de planejamento tributário, definição do preço de venda e de transferência gerencial. Estes dados, ao contrário do que foi apresentado no Fator quatro, vislumbra um entendimento de que a função do Controller não se limita a um conjunto de tarefas de execução, mas a sua importância na participação em atividades mais estratégicas da organização.

\section{Considerações Finais}

Entende-se que a controladoria nas organizações, inicialmente, teve suas funções relacionadas estritamente a área da contabilidade. Por outro lado, em uma visão mais contemporânea, a função da controladoria está assumindo um papel cada vez mais estratégico e de apoio a tomada de decisões organizacionais (Frezatti et al., 2009; Lourensi \& Beuren, 2011; Mondini et al., 2015).

Este estudo teve como objetivo analisar a variabilidade nas respostas dos graduandos do curso de ciências contábeis sobre a importância da função da controladoria nas organizações. Para isto, adotou-se uma abordagem quantitativa com base nas perspectivas teóricas dos estudos de Borinelli (2006), a análise descritiva, a técnica multivariada de análise fatorial exploratória e a multicriterial por meio da técnica de entropia da informação.

Os principais resultados indicaram que os 234 discentes do curso de Ciências Contábeis apresentaram variabilidade na percepção das atividades da controladoria nas empresas. A dimensão que apresentou maior variação foi a Dimensão 3 "Atividades e Funções da Controladoria Relativas ao Processo de Gestão" (presente nos Fatores 4 e 5). Os itens pertencentes a esta dimensão apresentaram uma concordância entre os graduandos que a atividade da controladoria está vinculada a funções operacionais, mas também há necessidade da participação do Controller em demandas estratégicas.

Outro aspecto importante foi o fato de os estudantes já terem atuado em empresas na área de controladoria não causou variabilidade nas respostas dos estudantes que não possuíam experiência profissional. Infere-se que a visão e experiência dos docentes do curso de ciências contábeis têm efeito na percepção dos seus discentes quanto a função da controladoria nas organizações. Apesar da variabilidade apontada, ainda é preponderante que a área é mais percebida como operacional do que estratégica.

Pôde-se averiguar que, ainda falta um amadurecimento na academia quanto ao papel da controladoria e as funções do controllers nas organizações. Percebe-se que os estudantes ainda entendem como sendo função da controladoria as atividades operacionais. Tal dado pode ser o reflexo de uma área relativamente nova, que ainda carece de estudos, conforme salientado por Lourensi e Beuren (2011). Entretanto a discussão quanto a discrepância no entendimento das funções atribuídas a controladoria nas organizações já ocorre há mais de 70 anos (Fiske, 1940).

Desta forma, sugere-se para estudos futuros que, as perspectivas de Borinelli, sejam utilizadas sob a análise que viabilize a adequação dos currículos dos cursos de bacharelado em ciências contábeis, do mesmo modo, para a averiguação da percepção dos docentes acerca das atribuições da controladoria nas organizações contemporâneas.

\section{Referências}

Almeida, A. T. (2013). Processo de decisão nas organizações: construindo modelos de decisão multicritério. São Paulo: Atlas. 
Anthony, R. N. (1965). Planning and Control Systems: A Framework for Analysis [by]. Division of Research, Graduate School of Business Administration, Harvard University.

Araújo, J. G. R., Callado, A. L. C.; \& Cavalcanti, B. S. B. (2014) Habilidades e Competências do Controller: um Estudo com Alunos de Cursos de Pós-graduação em Controladoria. Revista Catarinense da Ciência Contábil, 13(38), 52-64. https://doi.org/10.16930/2237-7662/rccc.v13n38p52-64

Beuren, I. M. \& Grande, J. F. (2008). Abordagens da Controladoria em Livros Publicados no Brasil. RIC Revista de Informação Contábil, 2(1).

Berry, A. J. (1994) Spanning traditional boundaries: organization and control of embedded operations. Leadership \& Organization Development Journal, 15(7), 4-10. https://doi.org/10.1108/01437739410066478

Carvalho Júnior, C. V. O. and Rocha, J. S. (2009) Controladoria no Brasil: um estudo a partir da perspectiva dos pesquisadores brasileiros. Revista de Administração e Contabilidade da FAT, 1(1), 4-19.

Collis, J. \& Hussey, R. (2013). Business research: A practical guide for undergraduate and postgraduate students. Palgrave Macmillan.

Corrar, L. J., Paulo, E. \& Dias Filho, J. M. (2007). Análise multivariada: para os cursos de administração, ciências contábeis e economia. São Paulo: Atlas, p. 280-323.

Fiske, W. P. (1940). Training for the controllership. The Accounting Review, 15(2), 232-238.

Frezatti, F. \& Kassai, S.(2003). Estudo do impacto de um curso MBA em controladoria na evolução de seus egressos. Revista Contabilidade \& Finanças, 14(SPE), 54-65. https://doi.org/10.1590/S1519$\underline{70772003000400003}$

Frezatti, F., Rocha, W., Nascimento, A. \& Junqueira. E. (2009). Controle Gerencial: uma abordagem da contabilidade gerencial, no contexto econômico, comportamental e sociológico. São Paulo: Atlas.

Gomes, C. V., Souza, P. \& Lunkes, J. R. (2014). O perfil do profissional da controladoria solicitado por empresas brasileiras. GCG-Globalización, Competitividad y Gobernabilidad, 8(1), 970.

Gomes, L. F., Autran, M., Araya, M. C. G. \& Carignano, C (2004). Tomada de decisões em cenários complexos: introdução aos métodos discretos do apoio multicritério a decisão. São Paulo: Thomson.

Hair, J. F. et al. (2009). Análise multivariada de dados. Bookman Editora.

Kaplan, R. S. \& N, David P. (2005). The balanced scorecard: measures that drive performance. Harvard Business School Publishing.

Lourensi, A. \& Beuren, I. M. (2011). Inserção da Controladoria em teses da FEA/USP: uma análise nas perspectivas dos aspectos conceitual, procedimental e organizacional. Contabilidade Vista \& Revista, 22(1)

Lowe, E. A (1971). On the idea of a management control system: integrating accounting and management control. Journal of Management Studies, 8(1), 1-12. https://doi.org/10.1111/i.1467-6486.1971.tb00833.x

Lowe, T. \& Puxty, T. (1989). The problems of a paradigm: a critique of the prevailing orthodoxy in management control. In: Critical perspectives in management control. Palgrave Macmillan UK, p. 9-26. https://doi.org/10.1007/978-1-349-07658-1 2

Lunkes, R. J., Gasparetto, V. \& Schnorrenberger, D. (2010). Um estudo sobre as funções da controladoria. Revista de Contabilidade e Organizações, 4(10), 106-126.

https://doi.org/10.11606/rco.v4i10.34779

Lunkes, R. J., et al. (2011). Funções da controladoria: Um estudo nas 100 maiores empresas do Estado de Santa Catarina. Análise Psicológica [online], 29(2), 345-361. https://doi.org/10.14417/ap.57

Lunkes, R. J. et al. (2012). Controladoria: um estudo bibliométrico no Congresso Brasileiro de Contabilidade de 2000, 2004 e 2008. Revista Brasileira de Contabilidade, 175, 24-37. 
Matzenauer, H.B. (2003). Avaliação da sustentabilidade ambiental de municípios Paraibanos: Uma aplicação utilizando o método PROMETHEE II. Tese de Doutorado Apresentada ao Programa de PósGraduação em Recursos Hídricos e Saneamento Ambiental da Universidade Federal do Rio Grande do Sul.

Macdonald, J. H. (1940). Controllership: its functions and technique: prepared for the Controllers' Institute of America. Controllers Institute of America.

Mondini, V. E. D., Tambosi, S. S. V. \& Lavarda, C. E. F. (2015). Atribuições da Controladoria e Função do Controller nas Organizações: Percepção dos Graduandos de Ciências Contábeis. Anais do XXXIX ENANPAD, 2015, Belo Horizonte. XXXIX ENANPAD.

Oro, I. M., Beuren, I. M., \& Carpes, A. M. (2013). Competências e habilidades exigidas do controller e a proposição para sua formação acadêmica. Contabilidade Vista \& Revista, 24(1), 15-36.

Otley, D. (1990). Issues in accountability and control: some observations from a study of colliery accountability in the British Coal Corporation. Management Accounting Research, 1(2), 101-123. https://doi.org/10.1016/S1044-5005(90)70048-0

Otley, D. (1994). Management control in contemporary organizations: towards a wider framework. Management Accounting Research, 5(3), 289-299. https://doi.org/10.1006/mare.1994.1018

Otley, D. (1999). Performance management: a framework for management control systems research. Management Accounting Research, 10(4), 363-382. https://doi.org/10.1006/mare.1999.0115

Paiva, J. C. L. S. \& Facci, N. (2014). O ensino da disciplina de controladoria: um estudo comparativo nas instituições de ensino superior do estado do Paraná. Revista Unifamma, 12(2).

Peleias, I. R. et al. (2011). Interdisciplinaridade no ensino superior: análise da percepção de professores de controladoria em cursos de ciências contábeis na cidade de São Paulo. Avaliação: Revista da Avaliação da Educação Superior, 16(3). https://doi.org/10.1590/S1414-40772011000300002

Rocha, I. et al. (2011). A presença da entropia da informação no controle orçamentário em ambiente inovador. RAI Revista de Administração e Inovação, 8(2), 82-105. https://doi.org/10.5773/rai.v8i2.566

Rodrigues, M. S. \& Amaral, M. S. (2006), O ensino da disciplina de controladoria nos programas de pósgraduação em nível de especialização em ciências contábeis e o profissional controller atuante no mercado de trabalho. Enfoque, 25(3). https://doi.org/10.4025/enfoque.v25i3.3456

Schnorrenberger, D.; Castro, G. K. \& Lunkes, R. J. (2015). Perspectivas profissionais do controller no Brasil e Espanha. Anais do Congresso Brasileiro de Custos- $A B C$.

Siegel, G. \& Kulesza, C. S. (1996a) The coming changes in management accounting education. Strategic Finance, 77(7), 43.

Siegel, G. \& Kulesza, C. S. (1996b). The practice analysis of management accounting. Strategic Finance, 77(10), 20.

Siegel, G., Kulesza, C. S. \& Sorensen, J. E. (1997). Are you ready for the new accounting? Journal of Accountancy, 184(2), 42.

Stewart, T. J. (2011). Multicriteria Decision Analysis. In: Lovric M. (eds) International Encyclopedia of Statistical Science. Springer Berlin Heidelberg. https://doi.org/10.1007/978-3-642-04898-2 384

Yoshitake, M. (1982). Funções do controller: conceitos e aplicações de controle gerencial. Dissertação (Mestrado em Ciências Contábeis) -Programa de Pós-graduação em Ciências Contábeis, Departamento de Contabilidade e Atuária, Faculdade de Economia, Administração e Contabilidade da Universidade de São Paulo, São Paulo.

Zeleny, M. (1982). Multiple Criteria Decision Making. McGraw-Hill, New York.

Zou, Z., Yi, Y.; Sun, J (2006). Entropy method for determination of weight of evaluating indicators in fuzzy synthetic evaluation for water quality assessment. Journal of Environmental Sciences, 18(5), 1020-1023. https://doi.org/10.1016/S1001-0742(06)60032-6 


\section{NOTAS}

AGRADECIMENTOS

Agradecimento à Coordenação de Aperfeiçoamento de Pessoal de Nível Superior (CAPES)

\section{CONTRIBUIÇÃO DE AUTORIA}

Concepção e elaboração do manuscrito: S.S.V. Tambosi, J.Tambosi Junior, N. Hein, A. Kroenke

Coleta de dados: S.S.V. Tambosi

Análise de dados: S.S.V. Tambosi, J.Tambosi Junior

Discussão dos resultados: S.S.V. Tambosi

Revisão e aprovação: S.S.V. Tambosi

\section{CONJUNTO DE DADOS DE PESQUISA}

Todo o conjunto de dados que dá suporte aos resultados deste estudo foi publicado no próprio artigo.

\section{FINANCIAMENTO}

O presente trabalho foi realizado com apoio da Coordenação de Aperfeiçoamento de Pessoal de Nível Superior - Brasil (CAPES) - Código de Financiamento 001.

\section{CONSENTIMENTO DE USO DE IMAGEM}

Não se aplica.

\section{APROVAÇÃO DE COMITÊ DE ÉTICA EM PESQUISA \\ Não se aplica.}

\section{CONFLITO DE INTERESSES}

Não se aplica.

\section{LICENÇA DE USO}

Os Direitos Autorais para artigos publicados neste periódico são do autor, com direitos de primeira publicação para a Revista. Em virtude de aparecerem nesta Revista de acesso público, os artigos são de uso gratuito, com atribuições próprias, em aplicações educacionais, de exercício profissional e para gestão pública. A Revista adotou a licença Creative Commons Atribuição 4.0 Internacional - CC BY NC ND. Esta licença permite acessar, baixar (download), copiar, imprimir, compartilhar, reutilizar e distribuir os artigos desde que com a citação da fonte, atribuindo os devidos créditos de autoria. Nesses casos, nenhuma permissão é necessária por parte dos autores ou dos editores. Autores têm autorização para assumir contratos adicionais separadamente, para distribuição não-exclusiva da versão do trabalho publicada nesta revista (ex.: publicar em repositório institucional ou um capítulo de livro).

\section{PUBLISHER}

Universidade Federal de Santa Catarina. Curso de Ciências Contábeis e Programa de Pós-graduação em Contabilidade. Publicação no Portal de Periódicos UFSC. As ideias expressadas neste artigo são de responsabilidade de seus autores, não representando, necessariamente, a opinião dos editores ou da universidade.

\section{EDITORES}

Carlos Eduardo Facin Lavarda e Suliani Rover

\section{HISTÓRICO}

Recebido em: 09/07/2018 - Revisado por pares em: 14/04/2020 - Reformulado em: 11/05/2020 Recomendado para publicação em: 15/10/2020 - Publicado em: 15/01/2021 